\title{
THE
}

\section{A Preliminary Full-Wave Ambient-Noise Tomography Model Spanning from the Juan de Fuca and Gorda Spreading Centers to the Cascadia Volcanic Arc}

Haiying Gao

Yang Shen

University of Rhode Island, y.shen@icloud.com

Follow this and additional works at: https://digitalcommons.uri.edu/gsofacpubs

Terms of Use

All rights reserved under copyright.

\section{Citation/Publisher Attribution}

Haiying Gao and Yang Shen. (2015). "A Preliminary Full-Wave Ambient-Noise Tomography Model Spanning from the Juan de Fuca and Gorda Spreading Centers to the Cascadia Volcanic Arc." Seismological Research Letters, 86(5).

Available at: http://dx.doi.org/10.1785/0220150103

This Article is brought to you for free and open access by the Graduate School of Oceanography at DigitalCommons@URI. It has been accepted for inclusion in Graduate School of Oceanography Faculty Publications by an authorized administrator of DigitalCommons@URI. For more information, please contact digitalcommons-group@uri.edu. 


\title{
Seismological Research Letters
}

\author{
This copy is for distribution only by \\ the authors of the article and their institutions \\ in accordance with the Open Access Policy of the \\ Seismological Society of America.
}

For more information see the publications section of the SSA website at www.seismosoc.org

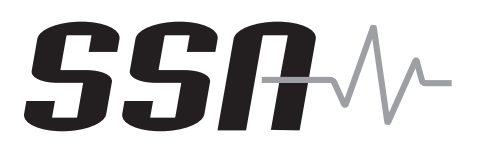

The Seismological Society of America

400 Evelyn Ave., Suite 201

Albany, CA 94706-1375

(510) 525-5474; FAX (510) 525-7204

WwW.seismosoc.org 


\section{A Preliminary Full-Wave Ambient-Noise Tomography Model Spanning from the Juan de Fuca and Gorda Spreading Centers to the Cascadia Volcanic Arc}

\section{by Haiying Gao and Yang Shen}

Online Material: Figures of $V_{S}$ structure and correlation with gravity lows and estimated slip patches, and resolution test.

\section{INTRODUCTION}

The Cascadia Initiative (CI) Amphibious Array provides us an unprecedented opportunity to investigate seismologically the formation, alteration, and subduction of the downgoing Juan de Fuca and Gorda plates, as well as the fore-arc and volcanic arc (Fig. 1). Formed at the spreading center, the oceanic crust undergoes normal faulting near the ridge axis. As the plate cools and moves away from the spreading center, the thermal stress and forces at the plate boundaries and the base of the plate may cause faulting and deformation in the plate interior. Near the subduction trench, the plate bends, forming cracks in the upper plate (e.g., Ranero et al., 2003). The faults and cracks provide pathways for fluid to penetrate deep into the crust and possibly mantle lithosphere (e.g., Nedimović et al., 2009), causing chemical reactions that alter the composition of the plate, including serpentinization of the mantle lithosphere (Melson and Thompson, 1971). As the plate subducts, fluid within the plate and in the entrained sediment is released progressively with increasing pressure and temperature, affecting the rheology and fault behavior at and near the plate interface and resulting in partial melting in the mantle wedge and volcanism along the arc (Ranero et al., 2003). To understand subduction zones, we must have a clear and complete picture of the fore-arc structure and the incoming plate at the trench, which in turn requires a good understanding of the interior of the plate.

There have been many seismic studies of the fore-arc crustal structure in the Cascadia subduction zone. Using earthquake arrivals and air-gun shots recorded by land-based receivers, Ramachandran et al. (2006) obtained a $P$-wave velocity structure of the northern Cascadia subduction zone, which shows relative low velocities above the slab at the crustal level and in the fore-arc mantle wedge. Both may partially reflect the effects of fluids. Calvert et al. (2011) observed a similar low- velocity zone above the slab and interpreted it as underthrusted sediments. Using ambient-noise correlations from the Cascadia Arrays for Earthscope broadband array in western Washington, Calkins et al. (2011) observed a zone of low $V_{S}$ above the portion of the slab expected to be undergoing dehydration reactions. These studies demonstrate that seismic tomography provides powerful constraints on the underthrusting of sediment, dehydration, and serpentinization in the mantle wedge. However, none of the previous studies provide a detailed and comprehensive 3D seismic velocity model that covers the entire Cascadia area from the spreading centers to the arc, particularly for the offshore portion of the fore-arc, which is relatively poorly imaged at present. Such a comprehensive model is critical for understanding the along-strike variations in the fore-arc basin structure, sediment underthrusting, dehydration, episodic tremor and slip, serpentinization in the mantle wedge, and their spatial correlation and causal relationships with the structure and hydration of the incoming Juan de Fuca and Gorda plates.

In this article, we present a preliminary $3 \mathrm{D}$ shear-wave velocity $\left(V_{S}\right)$ model, extending from the oceanic plate(s) to the Cascade arc, with the use of full-wave simulation and seismic ambient-noise tomography. Seismic data from the first threeyear CI ocean-bottom seismometers (OBSs) and simultaneous broadband inland stations (from 2011 to 2014) are analyzed. The integration of seismic stations offshore and onshore yields the first comprehensive model from the trench to the Cascade fore-arc constrained with the CI ambient-noise data.

\section{DATA QUALITY ANALYSIS}

To evaluate the CI seismic data, we extracted the empirical Green's functions (EGFs) from continuous seismic records in 2011-2014. All the data were requested from the Incorporated Research Institutions for Seismology Data Management Center, including for the CI Amphibious Array and inland broadband seismic stations. The EGFs between the station pairs are retrieved from the vertical-to-vertical component cross 
(a)

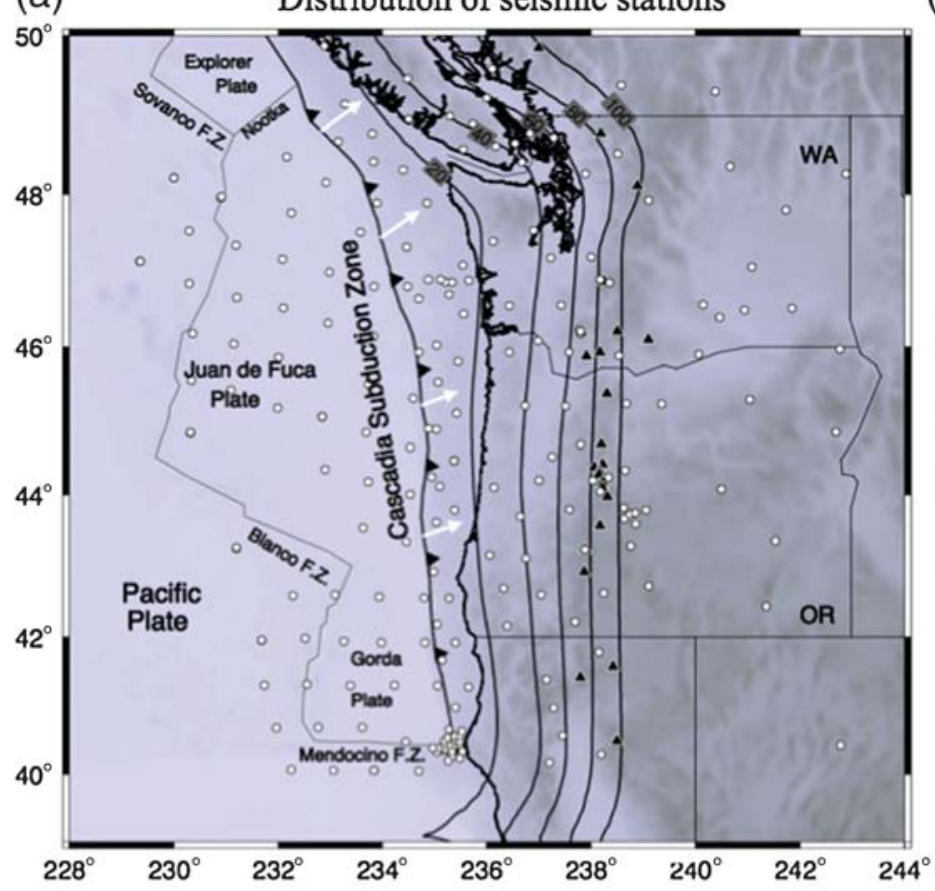

(b)

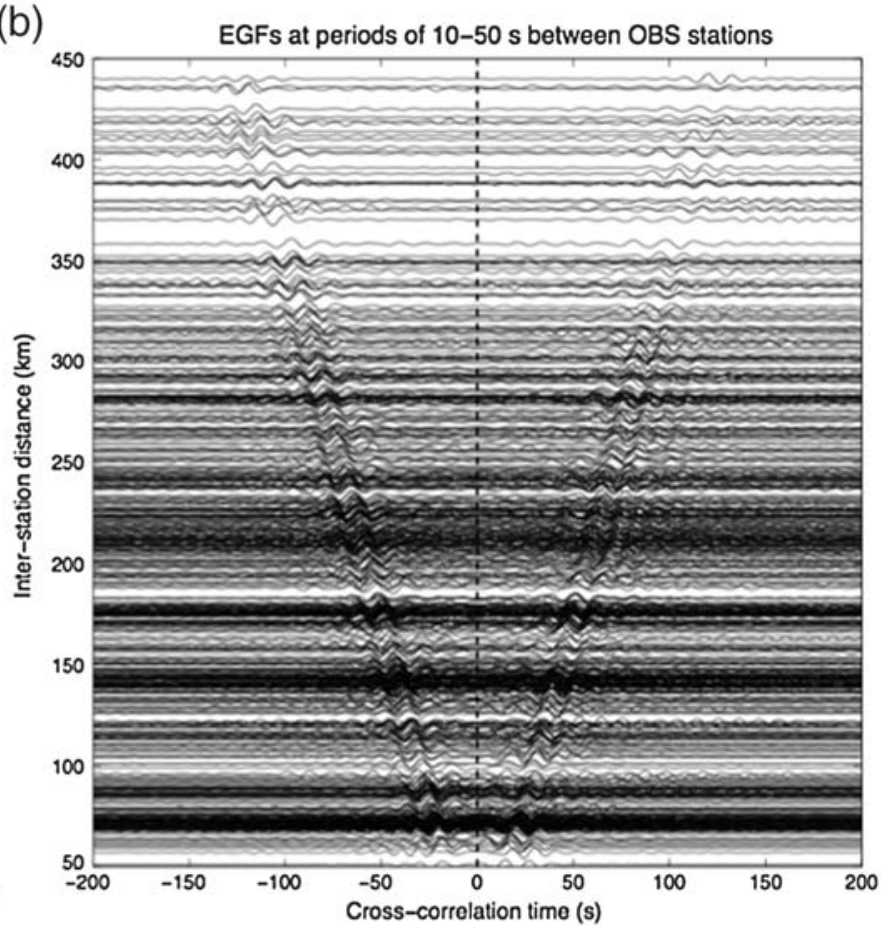

A Figure 1. (a) Distribution of seismic stations used in this study (white dots), including the first three-year Cascadia Initiative (CI) Amphibious Array and inland broadband stations. The depth contours of the Juan de Fuca plate, interfacing at $20 \mathrm{~km}$ intervals from 20 to $100 \mathrm{~km}$ depth, are from the model of McCrory et al. (2004). The black triangles mark the volcano centers. (b) Example of empirical Green's functions (EGFs), derived from ambient-noise cross correlation of vertical-to-vertical components between station pairs of $\mathrm{Cl}$ ocean-bottom seismometers (OBSs). The waveforms are filtered at periods of 10-50 s.

correlation of ambient noise. Prior to cross correlating ambient noise, we remove instrument response, cut the continuous record into a daily length, and resample the waveform to a uniform sample rate of 1 sample per second. The ambient-noise data are normalized in the time and frequency domains with a frequency-time-normalization method (Shen et al., 2012). We also eliminate time segments of large $\left(M_{\mathrm{w}}>5.5\right)$ earthquakes. To increase the signal-to-noise ratio (SNR), we stack daily cross correlations for each station pair. The EGFs are then recovered as the negative time derivative of the stacked cross correlations. In addition, we obtain monthly stacks of cross correlations, from which the variations provide estimates of the uncertainties of EGFs and their travel times.

The EGFs between the CI OBSs provide useful Rayleighwave signals within the periods of 7-50 s (Fig. 1), whereas the broadband inland seismic stations generate high-quality waveforms up to $100 \mathrm{~s}$ period. To quantitatively evaluate the quality of ambient-noise data, we calculate the average SNR of the EGFs from each station (considered as the virtual source) to all the others (as receivers). Distribution of the average SNR divides the data quality into three distinct zones from the deep water to the continent (Fig. 2a): (1) high-quality data for the inland broadband seismic stations, (2) good data for the seismic instruments in deep water, and (3) relatively poor and noisy data for the OBSs around the trench (small darker dots in Fig. 2a). The lack of long-period (>50 s) surface waves from the seafloor seismic instruments (Fig. 1b), as well as the data being relatively noisy (Fig. 2), are largely due to vertical seafloor deformation under the loading of long-period infragravity waves and tilt caused by bottom current (e.g., Webb and Crawford, 1999, 2010; Bell et al., 2014). Thus, the number of ray paths of Rayleigh waves used in seismic tomography varies substantially from trench to arc for different period ranges (Fig. 3). Correction for seafloor deformation due to long-period infragravity waves should significantly improve the surface-wave signal quality at long periods (50-100 s), in particular for OBS stations located between the coastline and the trench at shallow water (Webb and Crawford, 1999, 2010; Bell et al., 2014). In this preliminary study, we have not corrected for infragravity effects and tilt, and thus we focus on interpretation of our tomographic results in the crust and shallow mantle, a depth range constrained by Rayleigh waves at periods shorter than $50 \mathrm{~s}$.

\section{FULL WAVEFORM SIMULATION AND SEISMIC TOMOGRAPHY}

The procedure of the full-wave ambient-noise tomography includes finite-difference wave propagation simulation in the 3D Earth structure, measurement of phase delays between observed and synthetic waveforms, calculation of sensitivity kernels, and inversion for velocity perturbations. These steps are 
(a) Distribution of Signal-to-Noise Ratio

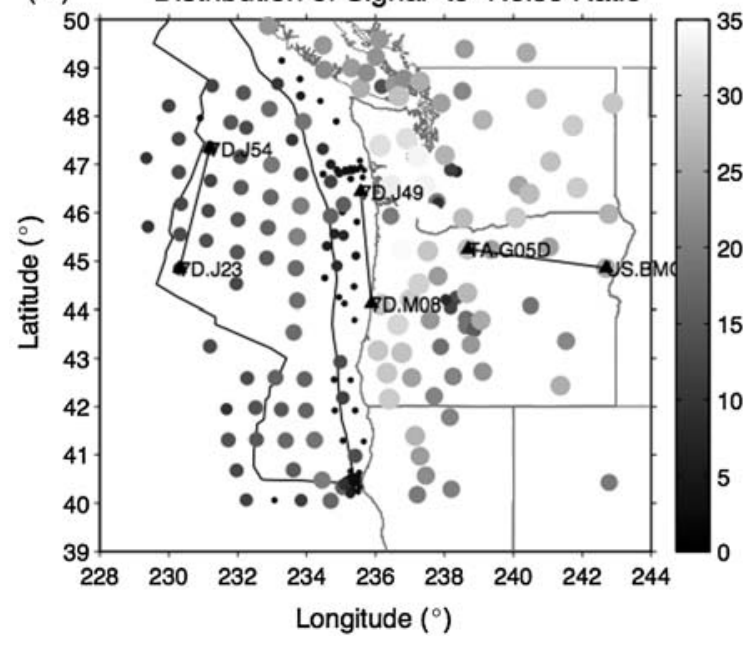

(b) Example of Seismic Waveforms

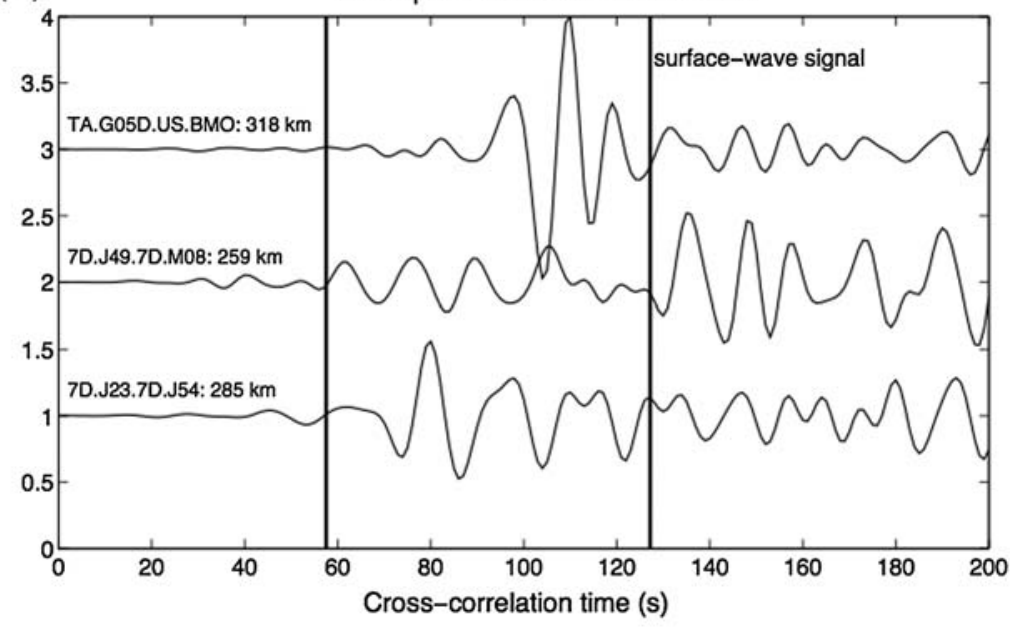

A Figure 2. Data quality of seismic waveforms. (a) Distribution of average signal-to-noise ratio (SNR) as represented by the shaded scale and the size of the symbol. Each dot represents the average SNR of EGFs from the station to all the others. Symbols with larger size in lighter color represent higher SNRs. Note the very low values (small dots in darker color) for OBSs located between the trench and the coastline. (b) Example of EGFs between three station pairs (see locations in a), filtered at periods of 10-50 s. The surface-wave signal is within the 60-120 s window. Note the poor data quality between station pairs 7D.J49 and 7D.M08, which are deployed in shallow water.

(a) Ray-Path Coverage at $50-100 \mathrm{~s}$

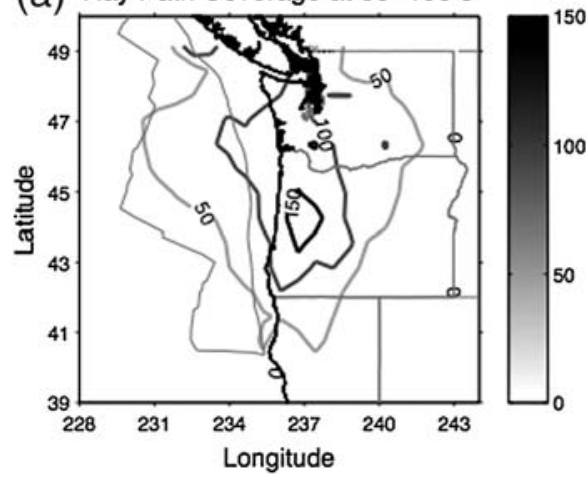

(b)

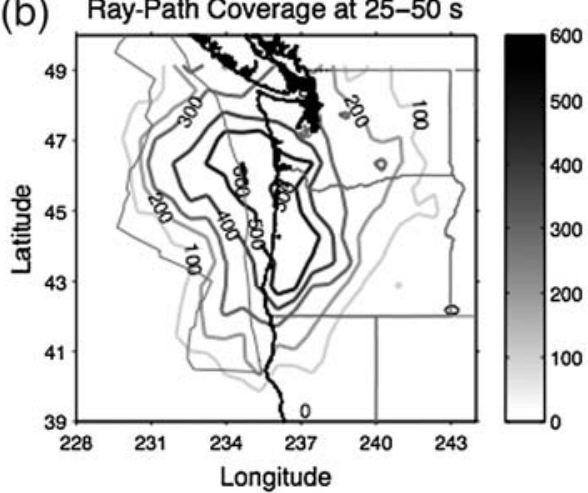

(c) Ray-Path Coverage at $10-25 \mathrm{~s}$

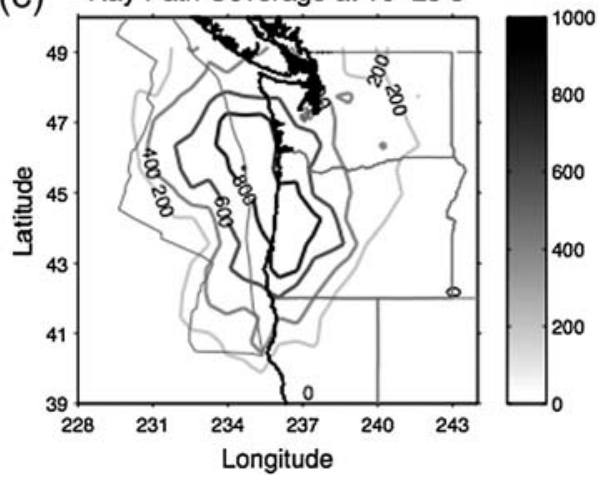

A Figure 3. Ray-path coverage used in full-wave ambient-noise tomography at periods of 50-100 s, 25-50 s, and 10-25 s, individually. The ray density is calculated for a cell size of $75 \mathrm{~km}$ along geographic longitude and latitude, the same as for the resolution test in Figure 6.

fully described by Gao and Shen (2014), so we only briefly summarize here.

We simulate wave propagation in the spherical Earth structure with a 3D nonstaggered-grid, finite-difference method. The initial reference model consists of two parts: a regional 3D shearwave velocity model by Gao and Shen (2014) for the onshore area and a combination of a global shear-velocity model of the crust and upper mantle (Shapiro and Ritzwoller, 2002) and the ak135 model (Kennett et al., 1995) at depths greater than $400 \mathrm{~km}$ for the offshore area. For computational reasons, we carry out two levels of finite-difference wave simulation and inversion, starting from a coarser grid for longer-period waves (correspondingly greater depths). The horizontal grid spacing for wave simulation is 5 and $2.5 \mathrm{~km}$ for levels 1 and 2, respectively, along the geographic longitude and latitude. The vertical grid spacing is about one-third of the horizontal spacing near the surface and increases with depth to approximately the same as the horizontal spacing at $\sim 100 \mathrm{~km}$ depth. Such grid sizes are sufficient to accurately simulate waves at periods longer than 20 and $10 \mathrm{~s}$ for levels 1 and 2, respectively (Zhang et al., 2012). The total wave propagation time in simulation is $500 \mathrm{~s}$, because the longest distance between stations is $\sim 1500 \mathrm{~km}$. To maintain numerical stability, we use a time step of $0.25 \mathrm{~s}$ for level 1 and $0.12 \mathrm{~s}$ for level 2. To calculate Green's functions, we use a Gaussian pulse with a half-width of 4 and 3 s, respectively, as the source time function of the vertical force applied at the virtual station. Our preliminary work does not consider anisotropy and attenuation in the wave simulation.

In this study, we cross correlate the EGFs with the corresponding synthetics within multiple period bands, in the ranges 

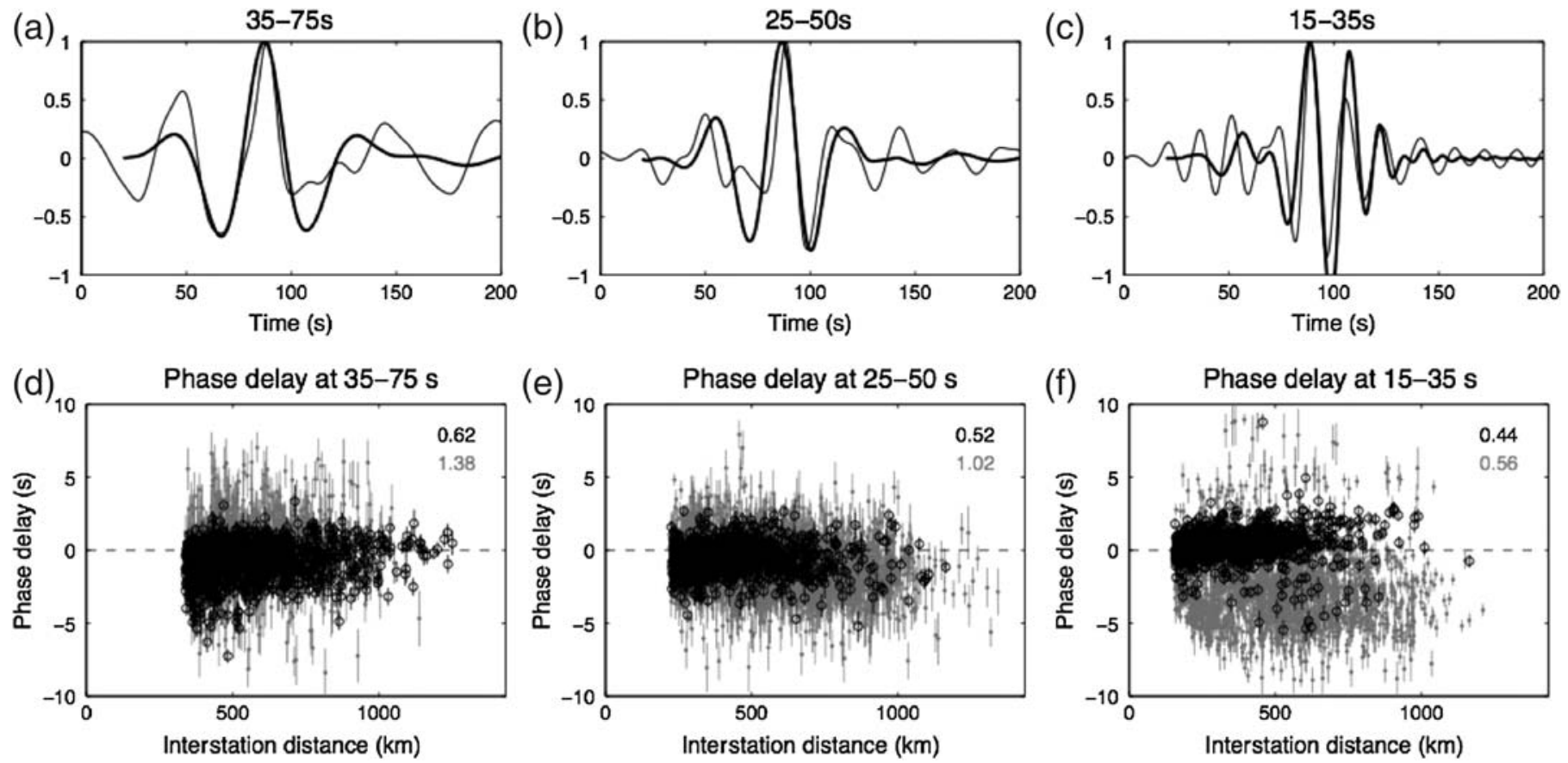

A Figure 4. (a-c) Comparison of observed EGFs (thin line) versus synthetics from the model after three iterations of inversion (thick line) between the station pair of 7D.J23 and 7D.J54, filtered at periods of 35-75 s, 25-50 s, and 15-35 s, respectively. (d-e) Phase delay between observed and synthetic waveforms with estimated uncertainty versus interstation distance at corresponding periods. Black circles denote measurements between inland broadband stations (the mean uncertainty is annotated as black), and gray dots denote measurements between $\mathrm{CI}$ OBS stations or between a CI OBS and an inland station (the mean uncertainty is annotated as gray). Phase delays of inland station pairs are less scattered and centered around zero, especially at shorter periods, reflecting higher SNRs of those data.

of 50-100, 35-75, 25-50, and 10-35 s (see e.g., Fig. 4). The source-receiver distance is required to be at least 1.5 -wavelength of the upper period limit within each band. To ensure a good amount of ray paths and high-quality signals, the criteria for the SNR of the seismic waveforms are set to be at least 2.5 between CI OBSs, 4 between each CI OBS-inland broadband station pair, and 8 between inland stations, respectively. The variable SNR ratios are necessary because a single fixed high value would lead to removal of all OBS pairs and a single fixed low value would result in an inversion dominated by measurements of inland station pairs. To avoid phase cycle skipping, we restrict the maximum cross-correlation lag time to the lower period limit within each period range. The sensitivity kernels are calculated with the strain-Green-tensor-based, scattering-integral method (e.g., Zhang et al., 2007). The inverse problem is solved with damping and smoothness constraints. The best-fit damping and smoothing parameters, which are gradually reduced with iterative inversions, are chosen from the trade-off of the normalized chisquared value and the model variance (Gao and Shen, 2012).

The model is progressively updated at each iteration with the recovery and open access of the CI data year by year. We started wave simulation and tomographic inversion for the northern part of the study area after the first year CI data were available. The model was then updated with two iterations. A year later, we extended the study area to cover the entire Juan de Fuca and Gorda plates with the recovery of year 1 data, for which we ran two more iterations. We then included data from year 3. In total, we have run a total of seven iterations with the two levels of finite-difference grid sizes.

\section{SEISMIC RESULTS AND RESOLUTION TESTS}

Here, we present the preliminary shear-wave velocity model. In general, the synthetic waveforms generated with the updated model can match with the observed data fairly well (Fig. 4). There still exists a weak linear trend between phase delays (measured between observed and synthetic waveforms) and interstation distances, especially at the shortest periods. Distribution of phase delays also appears to be more scattered between CI OBS stations (gray dots in Fig. 4) compared to inland broadband station pairs (black circles in Fig. 4), reflecting lower SNRs of OBS data. The linear trend at shorter period probably results from a poor constraint of the shallow crustal structure, which cannot be well resolved in this study considering the shortest periods and grid sizes used here. Nevertheless, in general our preliminary full-wave tomographic imaging (Fig. 5 and (E) electronic supplement to this article) agrees well with tectonic structures within the area. For example, we see the imaged subducting slab is approximately parallel to the projected plate interface from McCrory et al. (2004). Along the Cascade arc and the High Lava Plains, the seismic velocity is relatively low, indicating active magmatism in the crust and uppermost mantle within this area. The fast velocity off the Oregon coast in Figure 5b may indicate Siletzia offshore (Trehu et al., 1994; 
(a)

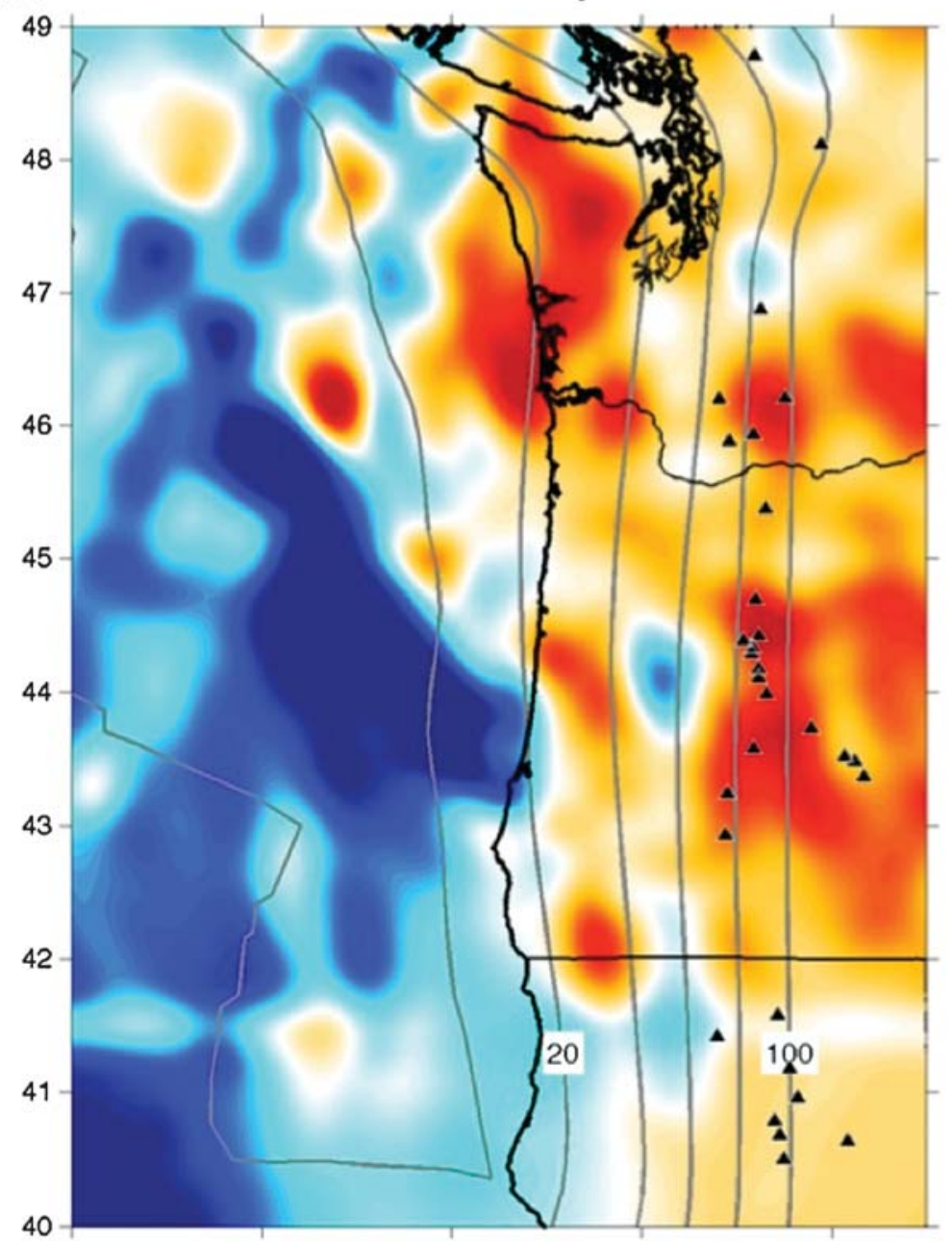

(b) Averaged $\mathrm{Vs}$ above the plate

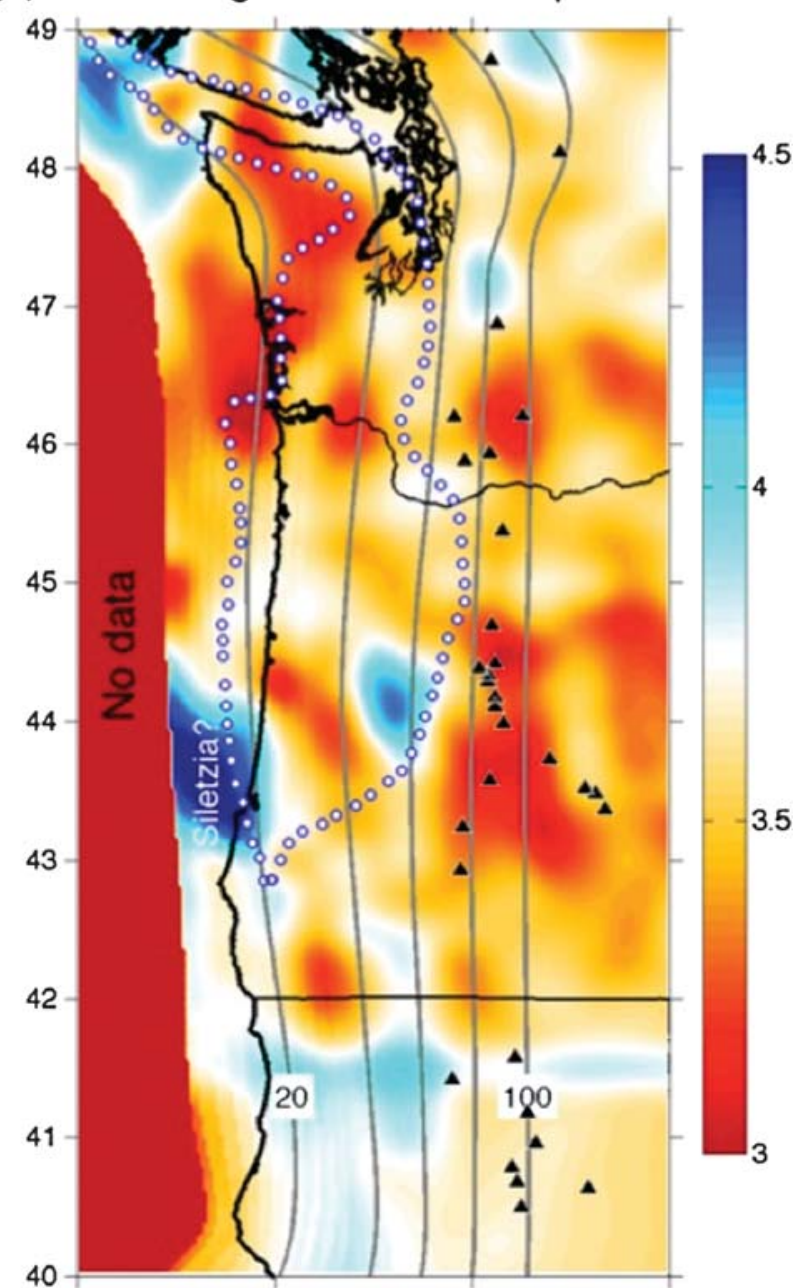

(c)

W-E profile along Latitude 46

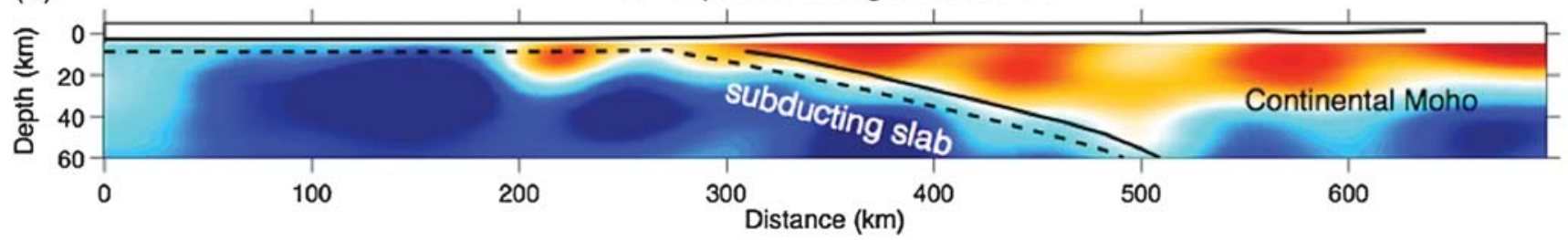

A Figure 5. Preliminary shear-wave velocity model in kilometers per second. (a) Shear-wave velocity model at $14 \mathrm{~km}$. (b) The averaged shear-wave velocity in the crust above the plate interface within 8-25 km depths. The white dots outline the distribution of Siletzia west of the Cascades from Wells et al. (1998). The black triangles indicate locations of Holocene volcanism. The gray lines are the depth contours of the Juan de Fuca plate interface at $20-100 \mathrm{~km}$ from the model of McCrory et al. (2004). (c) A west-east profile at latitude $46^{\circ}$. The projected plate interface is from McCrory et al. (2004). The dashed lines mark the oceanic Moho interface, assuming the average thickness of the oceanic crust of $6 \mathrm{~km}$.

Wells et al., 1998), though further study is required for a higher model resolution.

To assess the preliminary velocity model, we run several 3D resolution tests (Fig. 6 and (E) electronic supplement). We first run the $3 \mathrm{D}$ checkerboard resolution test having a $10-\mathrm{km}$-thick layer beneath the oceanic Moho (at 10-20 km depth) with a $\pm 10 \%$ velocity perturbation (Fig. 6 ). The velocity perturbation pattern is fairly well reconstructed at the depth of our interest, though the magnitude is underestimated due to damping in the inversion. We then use the resolved seismic velocity model as the input (see (E) Fig. S1). As shown in the electronic supplement, the velocity pattern of the input model is well reconstructed. We also ran a variety of checkerboard resolution tests with different cell dimensions and tested the effects of different input structures on the seismic results (see details in the electronic supplement). 
(a) Input at $30 \mathrm{~km}$

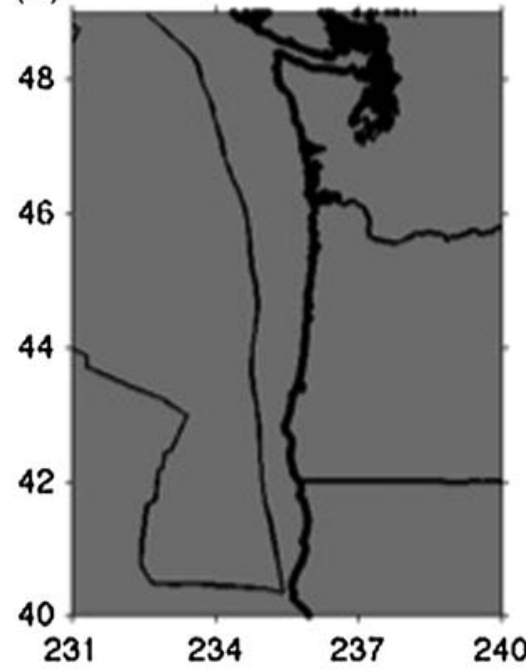

(d)

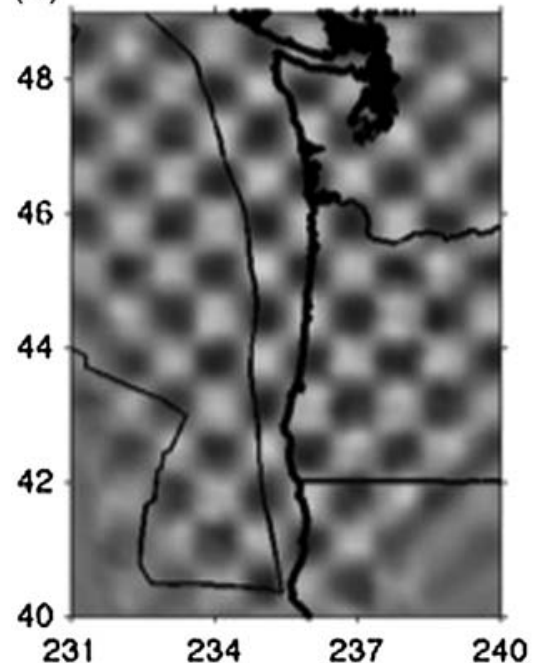

(b)

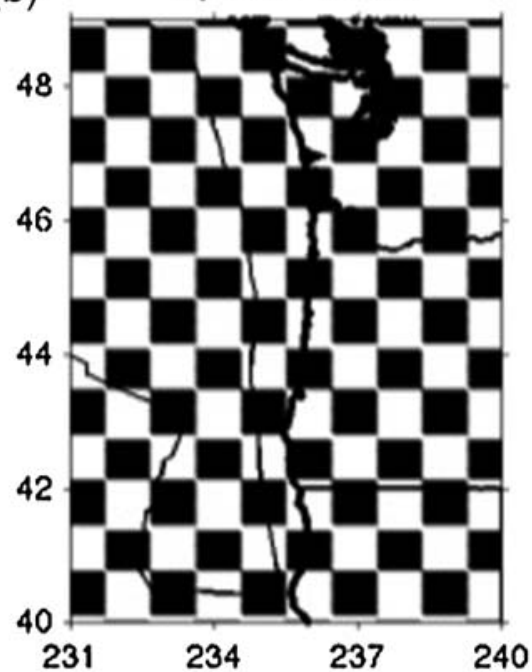

(e)

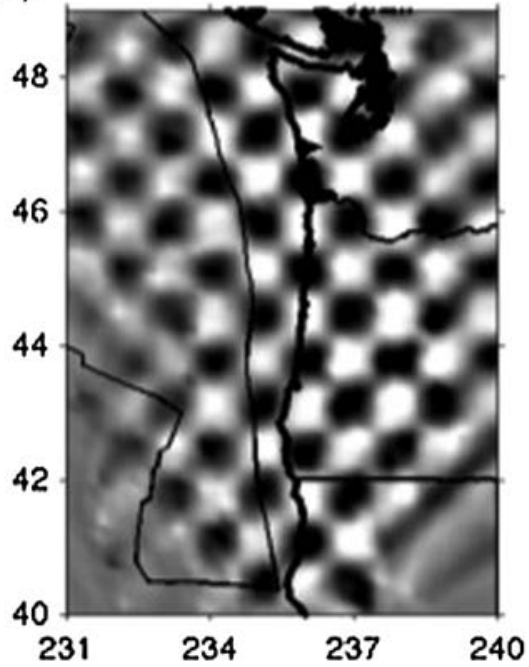

(c)

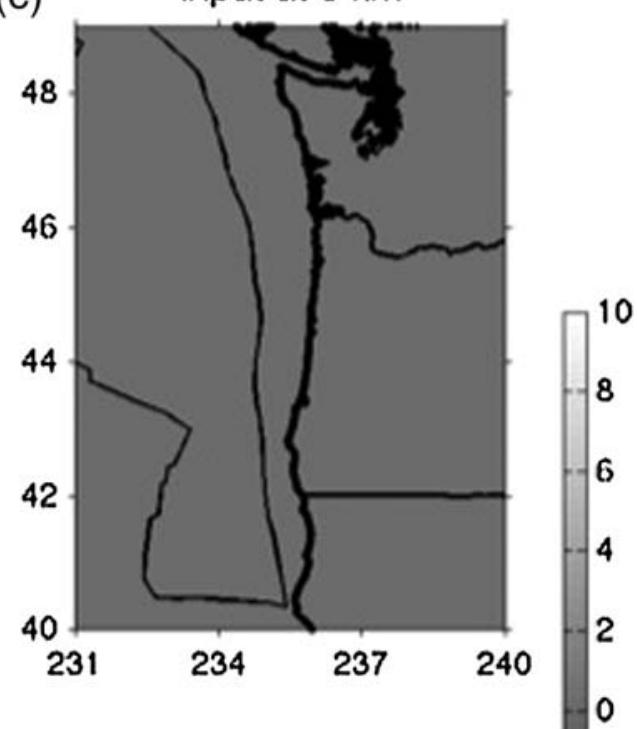

(f)

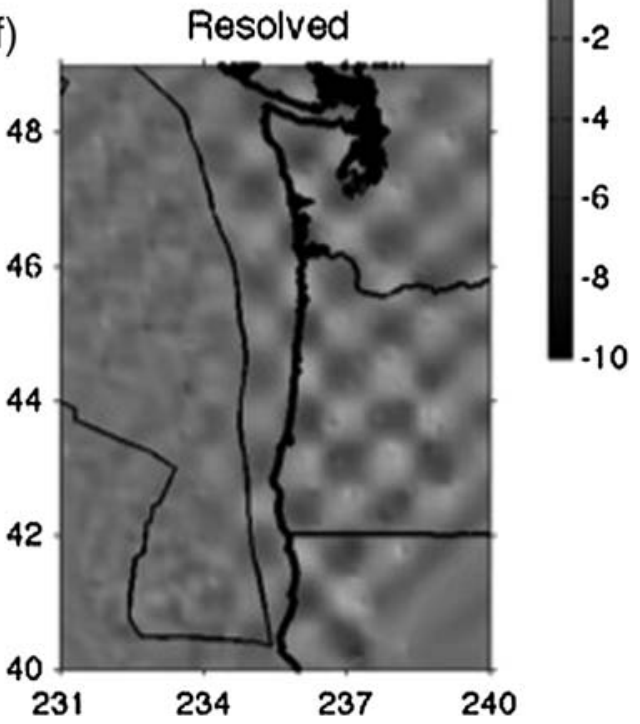

A Figure 6. Three-dimensional checkerboard resolution test. (a-c) The input model has a $10-k m$-thick layer with a $\pm 10 \%$ velocity perturbation at depths of 10-20 km beneath the oceanic Moho. The horizontal dimension of the checkerboard cells is $\sim 75 \mathrm{~km}$. (d-e) The recovered velocity models at the corresponding depths. As shown, the velocity perturbation pattern can be relatively well recovered, although the magnitude is underestimated.

In this article, we focus our discussion on two seismic lowvelocity features. First, we see segmented low-velocity anomalies along the fore-arc at shallow depths above the subducting plate (Fig. 5 and (E) electronic supplement). Our seismic imaging shows that the fore-arc low-velocity anomalies are stronger and wider in the north, where the plate bends, and the magnitude decreases significantly southward. The convergence rate and direction between the subducting plate and the continental plate vary along strike, which is relatively slow and more oblique in the south (e.g., Wang et al., 2001). The subduction zone exhibits an along-strike bend in northern Washington. In addition, the dip of the plate interface is shallower compared with the dip in central Oregon and northernmost California. This suggests that, because of the plate geometry, the subducting plate in the north is less erosive, resulting in the formation of relatively wider sedimentary basins on the fore-arc.

We observe some extent of spatial correlations of our low seismic velocities with the patterns of offshore basins (Wells et al., 2003) and high slip patches (Wang et al., 2013) as shown in the electronic supplement (ㅌ) Fig. S2). Landward of the trench, the segmented gravity anomalies indicate sediments in the fore-arc basins and transverse uplifts (Wells et al., 2003), which suggests substantial variations along strike (labeled as patches B, C, D, and E from north to south, see (E) Fig. S2). Most of the rupture patches and seismic moment (Wang et al., 2013) in the Pacific megathrust earthquakes occurred beneath prominent gravity lows, thus, determining the relation between the fore-arc basins and the incoming plate structure is impor- 
tant for understanding the seismogenesis. As demonstrated, the southern seismic low matches the gravity low patch $\mathrm{E}$ and the southern high-slip patch approximately well, whereas the central one is located north of the gravity low patch $\mathrm{D}$ and the high-slip patch off the Oregon coast. The northern seismic low roughly correlates with the gravity lows in patch B and part of $\mathrm{C}$, and with most of the high-slip patch off Washington. We infer that the three segmented seismic lows along the fore-arc may be related to the sedimentary basins that result from strong coupling between the subducting and overriding plates.

Second, the seismic velocity beneath the oceanic Moho near the trench is relatively low offshore Washington and northern Oregon (Fig. 5 and (E) electronic supplement material). Observations of anomalously low seismic velocities and densities of the uppermost mantle at several other subduction zones show evidence for pervasive serpentinization of mantle rocks linked to plate bending (e.g., Contreras-Reyes et al., 2008; van Avendonk et al., 2011). Thus, our observed heterogeneous seismic lows near the trench may indicate serpentinization of the oceanic mantle lithosphere as observed at other subduction zones. The tomographic result and corresponding interpretation are also consistent with previous studies in the region. Several observations suggest the presence of water within the Cascadia subduction zone system. For example, Preston et al. (2003) suggested that dehydration of the subducting slab results in the occurrence of intraslab earthquakes in Cascadia. Recent analysis of combined multichannel seismic reflection and wide-angle OBS data along a profile $\sim 10 \mathrm{~km}$ seaward of the Cascadia deformation front reveals lateral variations in mantle $P$-wave velocity between 7.5 and $8.2 \mathrm{~km} / \mathrm{s}$, suggesting along-trench variations in the state of alteration of the oceanic mantle lithosphere (Canales et al., 2013). However, due to the relatively poor vertical resolution at the depths of our interests (see (E) resolution tests in Figs. S3S9), quantitative details of serpentinization cannot be achieved, which are key to our understanding of the role of fluid in the along-strike variation of the subduction zone and need to be addressed further in the future.

\section{CONCLUSION}

In this study, we constructed a shear-wave velocity model extending from the spreading centers to the Cascade arc within the crust and uppermost mantle with the use of full waveform simulation and seismic ambient-noise tomography. We are able to extract useful Rayleigh-wave signals within periods of 7-50 s between the CI ocean-bottom seismic instruments. Dataquality analysis shows a relatively low average SNR of EGFs for OBSs in shallow water.

We imaged two seismic low-velocity features: (1) we see segmented low-velocity anomalies along the fore-arc at shallow depths above the subducting plate, and (2) the seismic velocity beneath the oceanic Moho near the trench is relatively low. Our tomographic result agrees roughly with tectonic structures within the study area and provides the context for understanding the subduction processes in Cascadia. An accurate mapping of the offshore fore-arc structure is also critical for the natural hazard assessment and understanding of seismogenesis. The model resolution in the preliminary work needs to be further improved, especially at shallow depths with short-period surface waveforms, to constrain the offshore and fore-arc structure as well as the corresponding geodynamic interpretations. Inclusion of shorter-period Rayleigh waves will result in an improved resolution of the model. In the future, we plan to remove the deformation and tilt noise from the vertical components of CI OBSs following the method described by Bell et al. (2014). We will also integrate arrivals from regional earthquakes. $\mathbf{Z}$

\section{ACKNOWLEDGMENTS}

All the seismic data were requested from the Incorporated Research Institutions for Seismology Data Management Center. The empirical Green's functions extracted from ambient noise, the synthetic seismic waveforms generated in this study, and the phase delays between the observed data and synthetic waveforms are available upon request to the authors. Comments from Guest Editor Susan Schwartz, SRL Editor-in-Chief Zhigang Peng, Managing Editor Mary George, and two anonymous reviewers significantly helped improve the manuscript. This research is supported by the National Science Foundation (Grant Number 1144771) and the startup support of Gao by the University of Massachusetts Amherst.

\section{REFERENCES}

Bell, S. W., D. W. Forsyth, and Y. Ruan (2014). Removing noise from the vertical component records of ocean bottom seismometers: Results from year one of the Cascadia Initiative, Bull. Seismol. Soc. Am. 105, no. 1, 300-313, doi: 10.1785/0120140054.

Calkins, J. A., G. A. Abers, G. Ekstrom, K. C. Creager, and S. Rondenay (2011). Shallow structure of the Cascadia subduction zone beneath western Washington from spectral ambient noise correlation, J. Geophys. Res. 116, no. B07302, doi: 10.1029/2010JB007657.

Calvert, A. J., L. A. Preston, and A. M. Farahbod (2011). Sedimentary underplating at the Cascadia mantle-wedge corner revealed by seismic imaging, Nature Geosci. 4, 545-548, doi: 10.1038/NGEO1195.

Canales, J. P., H. D. Carton, S. M. Carbotte, and M. R. Nedimovic (2013). Variations in seismic structure of the incoming Juan de Fuca plate along the Cascadia deformation front, American Geophysical Union (Fall Meet), Abstract S21C-2443.

Contreras-Reyes, E., I. Grevemeyer, E. R. Flueh, M. Scherwath, and J. Bialas (2008). Effect of trench-outer rise bending-related faulting on seismic Poisson's ratio and mantle anisotropy: A case study offshore of southern central Chile, Geophys. J. Int. 173, no. 1, 142156, doi: 10.1111/j.1365-246X.2008.03716.x.

Gao, H., and Y. Shen (2012). Validation of shear-wave velocity models of the Pacific Northwest, Bull. Seismol. Soc. Am. 102, no. 6, 26112621.

Gao, H., and Y. Shen (2014). Upper mantle structure of the Cascades with full-wave ambient noise tomography: Evidence for 3D mantle upwelling in the back-arc, Earth Planet. Sci. Lett. 309, 222-233, doi: $10.1016 /$ j.epsl.2014.01.012.

Kennett, B. L. N., E. R. Engdahl, and R. Buland (1995). Constraints on seismic velocities in the Earth from travel times, Geophys. J. Int. 122, $108-124$.

McCrory, P. A., J. L. Blair, D. H. Oppenheimer, and S. R. Walter (2004). Depth to the Juan de Fuca slab beneath the Cascadia subduction margin: A 3D model for sorting earthquakes, U.S. Geol. Surv. Data Series 91, http://pubs.usgs.gov/ds/91 (last accessed July 2015). 


\section{SRL Early Edition}

Melson, W. G., and G. Thompson (1971). Petrology of a transform fault zone and adjacent ridge segments, Phil. Trans. Roy. Soc. Lond. A 268, 423-441.

Nedimović, M. R., D. R. Bohnenstiehl, S. M. Carbotte, J. P. Canales, and R. P. Dziak (2009). Faulting and hydration of the Juan de Fuca plate system, Earth Planet. Sci. Lett. 284, 94-102, doi: 10.1016/ j.epsl.2009.04.013.

Preston, L. A., K. C. Creager, R. S. Crosson, T. M. Brocher, and A. M. Trehu (2003). Intraslab earthquakes: Dehydration of the Cascadia slab, Science 302, 1197-1200.

Ramachandran, K., R. D. Hyndman, and T. M. Brocher (2006). Regional P wave velocity structure of the northern Cascadia subduction zone, J. Geophys. Res. 111, no. B12301, doi: 10.1029/2005JB004108.

Ranero, C. R., J. P. Morgan, K. McIntosh, and C. Reichert (2003). Bending-related faulting and mantle serpentinization at the Middle America trench, Nature 425, 367-373.

Shapiro, N. M., and M. H. Ritzwoller (2002). Monte-Carlo inversion for a global shear velocity model of the crust and upper mantle, Geophys. J. Int. 151, 88-105.

Shen, Y., Y. Ren, H. Gao, and B. Savage (2012). An improved method to extract very broadband empirical Green's functions from ambient seismic noise, Bull. Seismol. Soc. Am. 102, no. 4, 1872-1877.

Trehu, A. M., I. Asudeh, T. M. Brocher, J. H. Luetgert, W. D. Mooney, J. L. Nabelek, and Y. Nakamura (1994). Crustal architecture of the Cascadia forearc, Science 266, 237-243, doi: 10.1126/science.266.5183.237.

Van Avendonk, H. J. A., W. S. Holbrook, D. Lizarralde, and P. Denyer (2011). Structure and serpentinization of the subducting Cocos plate offshore Nicaragua and Costa Rica, Geochem. Geophys. Geosyst. 12, no. 6, Q06009, doi: 10.1029/2011GC003592.

Wang, K., J. He, H. Dragert, and T. S. James (2001). Three-dimensional viscoelastic interseismic deformation model for the Cascadia subduction zone, Earth Planets Space 53, 295-306.

Wang, P.-L., S. E. Engelhart, K. Wang, A. D. Hawkes, B. P. Horton, A. R. Nelson, and R. C. Witter (2013). Heterogeneous rupture in the great Cascadia earthquake of 1700 inferred from coastal subsidence estimates, J. Geophys. Res. 118, 2460-2473, doi: 10.1002/jgrb.50101.
Webb, S. C., and W. C. Crawford (1999). Long-period seafloor seismology and deformation under ocean waves, Bull. Seismol. Soc. Am. 89, no. $6,1535-1542$.

Webb, S. C., and W. C. Crawford (2010). Shallow-water broadband OBS seismology, Bull. Seismol. Soc. Am. 100, no. 4, 1770-1778, doi: 10.1785/0120090203.

Wells, R. E., R. J. Blakely, Y. Sugiyama, D. W. Scholl, and P. A. Dinterman (2003). Basin-centered asperities in great subduction zone earthquakes: A link between slip, subsidence, and subduction erosion? J. Geophys. Res. 108, no. B10, doi: 10.1029/2002JB002072.

Wells, R. E., C. S. Weaver, and R. J. Blakely (1998). Fore-arc migration in Cascadia and its neotectonic significance, Geology 26, 759-762.

Zhang, W., Y. Shen, and L. Zhao (2012). Three-dimensional anisotropic seismic wave modeling in spherical coordinate by a collocated-grid finite difference method, Geophys. J. Int. 188, 1359-1381, doi: 10.1111/j.1365-246X.2011.05331.x.

Zhang, Z., Y. Shen, and L. Zhao (2007). Finite-frequency sensitivity kernels for head waves, Geophys. J. Int. 171, 847-856.

Haiying Gao

Department of Geosciences

University of Massachusetts Amberst Amberst, Massachusetts 01003 U.S.A. haiyinggao@geo.umass.edu

\section{Yang Shen \\ Graduate School of Oceanography University of Rhode Island Narragansett, Rhode Island 02882 U.S.A.}

Published Online 19 August 2015 